\section{Use of laparoscope as rigid enteroscope in blue rubber bleb naevus syndrome}

\author{
Stephen David Adams, ${ }^{1}$ Rebecca Lisle, ${ }^{1}$ \\ Tracy Coelho, ${ }^{2}$ Aroonkumar Chouhan, ${ }^{1}$ \\ Assad Butt, ${ }^{2}$ Anies A. Mahomed' \\ Departments of ${ }^{1}$ Paediatric Surgery and \\ ${ }^{2}$ Gastroenterology, Royal Alexandra \\ Children's Hospital, Brighton, UK
}

\section{Abstract}

Management of bleeding multiple haemangiomata within the gastrointestinal tract is a surgical challenge in this case of Blue Rubber Bleb Naevus Syndrome (BRBNS). Described is a novel use of the laparoscope as a rigid enteroscope in order to provide intraluminal imaging for successful lesional resection from small bowel.

\section{Introduction}

The management of chronic bleeding from multiple sources within the gastrointestinal tract is a surgical challenge particularly for areas not accessible via upper and lower gastrointestinal endoscopy. The laparoscope is adapted as a rigid enteroscope to enable assessment of the small and large bowel in a case of BRBNS. The technique provides surprising versatility for endoluminal imaging and facilitates the performance of surgery with resection of the majority of lesions.

\section{Case Report}

Presented is a case of a 14-year-old Caucasian male with multiple congenital venous malformations consistent with Blue Rubber Bleb Naevus Syndrome (BRBNS), also known as Bean Syndrome.

The patient was born at term after a normal pregnancy, and uncomplicated vaginal delivery. Soon after delivery he became stridulous. On laryngoscopy, a large soft tissue mass was noted on the right of his larynx, displacing the vocal cords, he was intubated and further investigation demonstrated the mass to be a supraglottic haemangioma. The lesion was treated with endoscopic laser therapy, but unfortunately recurred necessitating a tracheostomy. He was kept under medical and ENT review and regular microlaryngoscopy and bronchoscopy showed the mass to be enlarging with imminent airway obstruction. This has been treated by means of embolisation, laser therapy and more recently, sclerotherapy, with some benefit.

Iron deficiency anaemia has been noted from age 5, initially treated with oral iron supplementation. It was felt that the neck mass was the source of occult blood loss; however two strongly positive faecal occult blood tests led the investigation to the gastrointestinal (GI) tract. A radiolabelled Meckel's scan was reassuring and investigation did not proceed at this stage. During an elective admission for endoscopic examination of his larynx, he was found to have a haemoglobin of $4.4 \mathrm{~g} / \mathrm{dL}$ and treated with red cell transfusion. By age 10 he had received 44 separate blood transfusions and was having three weekly iron transfusions. Despite this he continued to run a borderline haemoglobin level between 5-9 g/dL.

At 11 years of age, due to ongoing occult blood loss, he was referred to gastroenterology. A barium meal with follow through showed no lesions, an upper GI endoscopy (Figure 1) and colonoscopy identified some vascular malformations in the small bowel and colon, this was confirmed by an MRI scan. Subsequent to that, a capsule endoscopy (Figure 2) identified numerous small bowel haemangiomas with active bleeding.

A diagnosis of intestinal angiodysplasia was made and conservative management advised. of the therapies tried, which included Octreotide and Tranexamic acid, only Thalidomide appeared to be of any benefit. After failed conservative treatment and further specialist review, the diagnosis was in fact felt to meet the criteria for BRBNS and surgical referral was pursued.

The evidence was reviewed and a surgical approach decided upon whereby the entire bowel could be visualised endoluminally and complete resection of all naevi attempted.

\section{Operative technique}

A midline laparotomy was performed and the bowel sequentially examined from the duodenal-jejunal flexure. The first lesion was identified just distal to the ligament of Treitz and a wedge excision performed. This site was then used as an enterotomy to allow insertion of a 0 degree $10 \mathrm{~mm}$ laparoscope via a port (Figure 3).

A purse string applied at the point of entry of the port into the bowel secured against air leaks and an isolated segment of bowel, with clamp applied distally, was distended by air insufflation down the port. Bowel was intussuscepted over the laparoscope to the distal limits of the isolated segment then slowly released and examined in retrograde fashion. The 0 degree scope allowed for comprehensive inspection of the circumference of the gut.

As lesions were encountered (Figure 4) a
Correspondence: Anies Mahomed, Department of Paediatric Surgery, Royal Alexandra Children's Hospital, Eastern Road, Brighton, BN2 5BE, UK. Tel. +34.01273.696955 - Fax: +3.01273.523120.

E-mail: anies.mahomed@bsuh.nhs.uk

Key words: small bowel, haemangioma, laparoscope, blue rubber bleb naevus syndrome.

Contributions: SDA, RL, main manuscript preparation; TC, provided gastroenterology perspective; $\mathrm{AC}$, patient history writing; $\mathrm{AB}$, gastroenterology opinion and advice; AAM, responsible for conception, editing and oversight.

Received for publication: 4 August 2011. Accepted for publication: 28 August 2011.

This work is licensed under a Creative Commons Attribution NonCommercial 3.0 License (CC BYNC 3.0).

(C) Copyright S.D. Adam et al., 2011

Licensee PAGEPress, Italy

Surgical Techniques Development 2011; 1:e12 doi:10.4081/std.2011.e12

serosal marker was placed followed by a transmural wedge excision of each. This procedure was repeated along the entire length of the small bowel and colon, with the most distal lesion being used as the new enterotomy site.

The lesions appeared as reddish blue protrusions into the gut and were of variable size. In total 20 lesions were excised (13 small bowel, 7 colon) in an operative time of $6 \mathrm{~h}$ (Figure 5). There were no intra or postoperative complications and the patient made an uneventful recovery with discharge on day 11 post surgery. Pathology of these lesions is in keeping with congenital venous malformations as seen in BRBNS.

\section{Follow-up}

At 6-month follow-up this boy had progressed well and describes feeling markedly better. He remained transfusion dependent but at a rate reduced from 4 units per month to around 1 to 1.5 units per month. This was accounted for by ongoing losses from a known lesion in the second part of the duodenum. A further upper GI endoscopic procedure with laser ablation has been undertaken to treat this lesion. 6 months later he no longer requires routine transfusion. He may continue to lose some blood from his known pharyngeal lesions but this is clearly a small volume, if it becomes problematic he may undergo laser ablation of via an ENT endoscopic procedure. 


\section{Discussion}

The association between haemangioma of the skin and the gastrointestinal tract was first described by Gascoyen in $1860^{1}$ and later characterised by Bean ${ }^{2}$ who described its features as bluish vascular naevi of the skin, venous malformation of the gut and gastrointestinal haemorrhage. Although most cases occur sporadically there are cases of autosomal dominant inheritance reported, and this has been linked to a mutation on chromosome $9 \mathrm{p} .^{3}$

The lesions may occur anywhere in the gastrointestinal tract from the mouth to the anus. They commonly occur in the skin, however they may also occur in other locations such as the peritoneal cavity, heart, lungs, pleura, CNS and eyes. ${ }^{4-6}$ The most common presentation of the condition is with chronic microcytic anaemia from occult bleeding, although acute sudden haemorrhage with malaena or haematochezia can occur. Other complications of the condition include intussussception, volvulus and haematological complications such as thrombocytopenia and disseminated intravascular coagulation. There have been no reported malignancies arising within a gastrointestinal lesion.

The treatment of BRBNS is initially conservative with iron supplementation and blood transfusion. Medical therapies including the use of interferon, corticosteroids and antifibrinolytics have been largely unsuccessful. ${ }^{7}$

Several interventional approaches have been reported in the literature. The use of endoscopy has been widely described. Three reported treatment options are thermal coagulation, sclerotherapy and polypectomy. The sole use of endoscopy is limited due to its accessibility to the lesions, which can only be accessed in the oesophagus, stomach, proximal duodenum and colon. As most lesions have been reported to be in the small bowel a combined surgical approach with intraoperative endoscopy is favoured. In patients where the entire bowel is not visualised there is a high risk of re-bleeding and further transfusion requirements.

Several forms of thermal coagulation have been described, Nd-YAG laser, argon plasma coagulation, and electrocautery. Initial reports showed argon plasma coagulation to be easy to perform, safe and effective..$^{8,9}$ The initial shallow coagulation forms an insulating layer, which limits penetration of the entire bowel wall. ${ }^{8}$ However a follow up paper by $\mathrm{Ng}$ and Wong have reported incidence of perforation with its use in larger lesions. ${ }^{10}$ Endoscopic polypectomy also has the benefits of being simple to perform and quick to use, however its risks include bleeding which may be difficult to control. Perforation is a serious complication especially in transmural lesions where wedge excision is required. Endoscopic sclerotherapy is ineffective and can lead to ulceration and scarring. ${ }^{11}$

The technique we employed in the described case offers several advantages over existing approaches. Firstly, control of the telescope and the rate at which the bowel is inspected is entirely at the behest of the surgeon and dispenses with the requirement for an endoscopist. Furthermore, the maneuverability of a rigid scope in a short segment of bowel allows for comprehensive examination of the intraluminal aspect of the gut and questionable areas are easily re-examined. Also, the views obtained through a 0 degree endoscope with magnification are excellent and picture integration to adjustable screens allows for a degree of versatility not experienced with endoscopic stack systems. The haemangioma once identified are accurately tagged and comprehensively excised. All these advantages translate into improved operational efficiency and shorter theatre time, which is critical in this context.

Recurrences of gastrointestinal lesions have

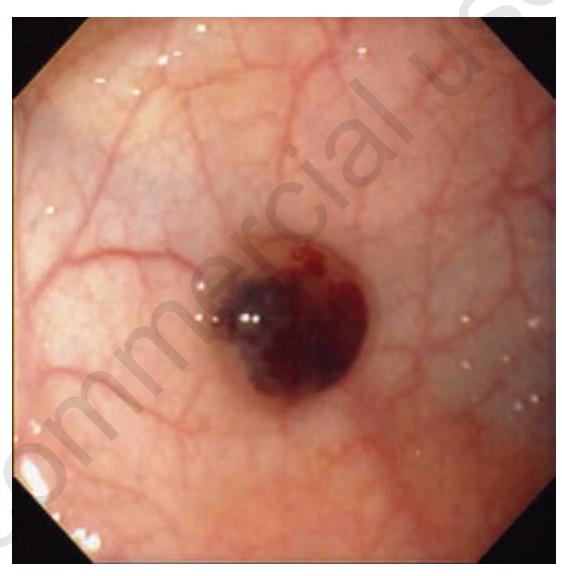

Figure 1. Large bowel venous malformation as noted at colonoscopy.

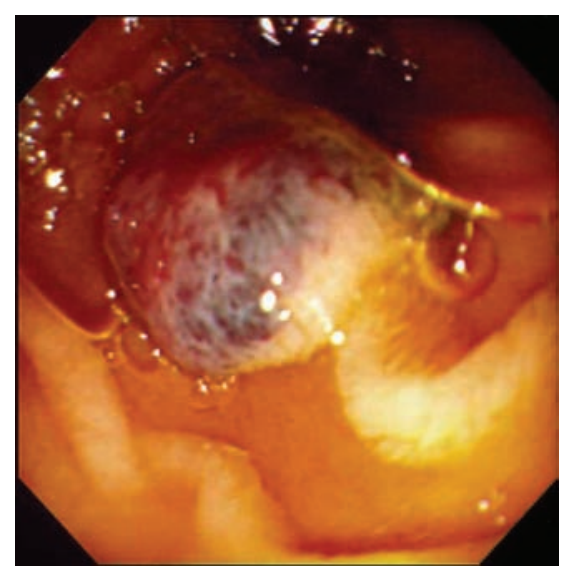

Figure 2. Capsule endoscopy demonstrating small bowel lesion. been reported, however it is unclear whether these are due to incomplete resection or if these lesions were not visualised during the initial procedure..$^{12,13}$ The lesions characterised in blue rubber bleb nevus syndrome have been biologically classified as vascular malformations and hence once fully resected, should not recur. This is important when considering the case for aggressive surgical resection. In the largest published case series (10 patients) by Fishman et al., all patients underwent aggressive surgical resection via several techniques, only one patient developed a further transfu-

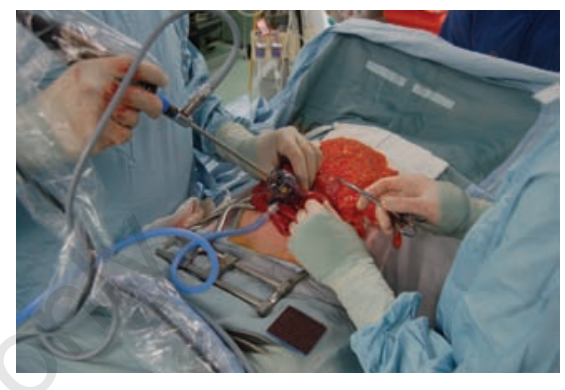

Figure 3. Introduction of laparoscopic endoscope through port into small bowel. A purse string suture around the port secures an air seal.

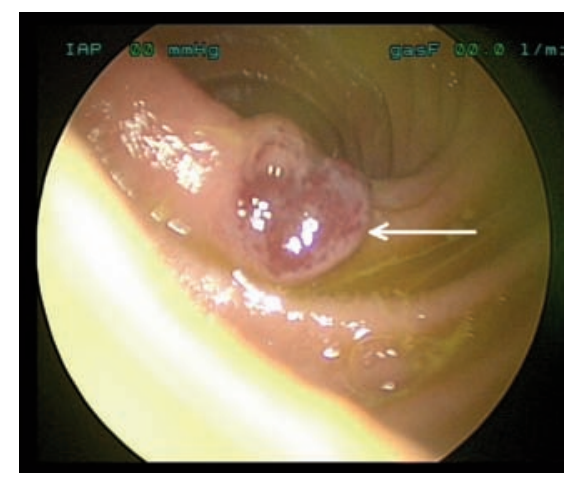

Figure 4. View of small bowel haemangioma (arrowed) obtained through a laparoscopic endoscope.

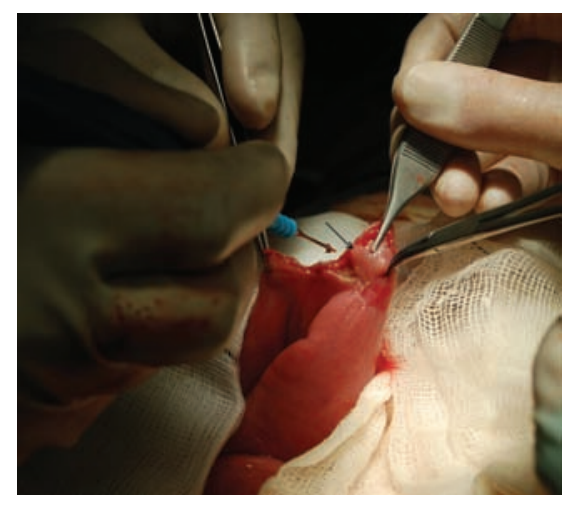

Figure 5. Enterotomy and resection of haemangioma (arrowed). 
sion requirement and this patient did not have intraoperative enteroscopy performed hence initial lesions may have been missed. The remainder all reported normal haemoglobin levels at follow up. ${ }^{14}$

The importance of visualising the entire intraluminal surface of the bowel is reinforced by our experience where the majority of lesions were only visible with the assistance of the endoluminal laparoscope. A previous report by Kopacova et al. also confirmed that smaller lesions ( 60 out of 72 in total) were only visible on the intraluminal surface. This is in contrast to previous reports where resections were performed only on lesions present on the serosal surface.

\section{Conclusions}

Our case highlights a novel use of the laparoscope as rigid enteroscope in order to provide intraluminal imaging which appears to be a necessity in the treatment of BRBNS. This combination of comprehensive imaging and aggressive surgical resection, although operatively and anaesthetically demanding offers the best opportunity for improved quality of life and potential cure from a complex and debilitating disease.

\section{References}

1. Gascoyen M. Case of naevus involving the parotid gland, and causing death from suffocation. Naevi of the viscera. Trans Pathol Soc (Lond) 1860;11:267.

2. Bean WB. Blue rubber-bleb nevi of the skin and gastrointestinal tract. In: Bean WB. Vascular Spiders and Related Lesions of the Skin. Springfield, IL: Charles C Thomas; 1958. pp. 17-185.

3. Gallione CJ, Pasyk KA, Boon LM, et al. A gene for familial venous malformations maps to chromosome 9p in a second large kindred. J Med Genet 1995;32:197-9.

4. Gilbey LK, Girod CE. blue rubber bleb nevus syndrome: endobronchial involvement presenting as chronic cough. Chest 2003;124:760-3.

5. Crompton JL, Taylor D. Ocular lesions in the blue rubber bleb naevus syndrome. $\mathrm{Br}$ J Ophthalmol 1981;65:133-7.

6. Waybright EA, Selhorst JB, Rosenblum WI. Blue rubber bleb nevus syndrome with CNS involvement and thrombosis of a vein of galen malformation. Ann Neurol 1978;3: 464-7.

7. M Domini, A Aquino, A Fakhro. Blue rubber bleb nevus syndrome and gastrointestinal haemorrhage: which treatment? Eur J Pediatr Surg 2002;12:129-33.

8. Ng EK, Cheung FK, Chiu PW, Blue Rubber Bleb Nevus Syndrome: Treatment of multiple gastrointestinal hemangiomas with argon plasma coagulator. Dig Endosc 2009;21:40-2.

9. Manoury V, Turck D, Brunetaud JM. Blue Rubber Bleb Nevus Syndrome. Trois cas traits par laser Nd: YAG et électrocoagulation bipolaire. [Blue rubber bleb nevus syndrome. 3 cases treated with a Nd:YAG laser and bipolar electrocoagulation]. Gastroenterol Clin Biol 1990;14:593-5.

10. Ng WT, Wong YT. Blue rubber bleb nevus syndrome: more lessons to be learnt. Eur J Pediatr Surg 2007;17:221-2.

11. Place RJ. Blue rubber bleb nevus syndrome: a case report with long term followup. Mil Med 2001;166:728-30.

12. Carr MM, Jamieson CG, Lal G. Blue rubber bleb nevus syndrome. Canad J Surg 1996; 39:59-62.

13. Shahed M, Hagenmüller, Rösch T, et al. A 19-year-old Female with blue rubber bleb nevus syndrome: endoscopic laser photocoagulation and surgical resection of gastrointestinal angiomata. Endoscopy 1990; 22:54-6.

14. Fishman SJ, Smithers CJ, Folkman J. Blue rubber bleb nevus syndrome: surgical eradication of gastrointestinal bleeding. Ann Surg 2005;241:523-8.

15. Kopacova M, Tacheci I, Koudelka J, et al. A new approach to blue rubber bleb nevus syndrome: The role of capsule endoscopy and intra-operative enteroscopy. Pediatr Surg Int 2007;23:693-7. 